\title{
The oil and gas industry must break the paradigm of the current exploration model
}

\author{
Cleveland M. Jones ${ }^{1}$
}

Received: 27 December 2016/ Accepted: 25 September 2017/Published online: 11 October 2017

(C) The Author(s) 2017

\begin{abstract}
An analysis of the exploration model that the oil and gas industry currently follows suggests that it often restricts innovation and inhibits exploration efforts. Examples of large, underexplored areas with significant oil and gas potential demonstrate how the current exploration model fails to allow adequate exploration efforts to be conducted. A description of a possible new exploration model is presented, involving the use of exploration technologies already available, as a means of breaking the paradigm of the current exploration model. Results of recent applications of such a model suggest that it can be applied both onshore and offshore, and that it is effective in detecting anomalies associated with significant hydrocarbon accumulations. Employing the new exploration model proposed, it was possible to effectively identify $99 \%$ of known hydrocarbon accumulations, although it was most effective at detecting hydrocarbon accumulation anomalies with a linear extent of over $2 \mathrm{~km}$, and it also allowed a valuable ranking of the identified leads. In conjunction with appropriate exploration tools, it reduced exploration risk by avoiding "false alarms," since it can effectively indicate areas without hydrocarbon potential, even when other geophysical tools would suggest prospectivity. These results suggest that the proposed alternative exploration model can provide a more direct means of assessing the hydrocarbon potential of large exploratory areas, even before other geophysical investigations provide detailed information on possible targets. Breaking the paradigm of
\end{abstract}

Cleveland M. Jones

clevelandmjones@gmail.com

1 INOG (Instituto Nacional de Óleo e Gás/CNPq), FGEL Geology Department/UERJ - State University of Rio de Janeiro, Rio de Janeiro, RJ, Brazil the current exploration model may thus be able to shorten the exploration cycle, reduce costs and allow resource development to proceed in frontier regions that would not otherwise be likely to attract exploratory efforts.

Keywords Oil and gas - Exploration model - Exploratory cycle - Geophysical survey - Hydrocarbon prospecting . Non-seismic tools

\section{Introduction}

As currently practiced, the exploration model that the oil and gas industry follows condemns it to a long and onerous process, before reaching conclusions regarding the prospectivity potential of those regions. The process of identification of prospective areas and risk reduction assessments, conducted prior to drilling the first exploratory well, can take years and require investments on a scale that the industry cannot currently justify. Due to the cost, delay and risk involved in such exploratory campaigns, many possibly attractive areas are left unexplored for long periods. Historically, in times of crises, paradigms have been broken and new business models have been adopted. Faced with a difficult economic scenario and the challenge of immense frontier areas to be prospected, together with high exploratory project risks, the oil and gas industry again needs to break a paradigm and adopt a new exploration model. A new exploration model should allow a faster, less expensive and more direct way of assessing the prospectivity of large exploratory areas and of identifying oil and gas leads. New and emerging technologies are the key to achieving this change. If the industry is to overcome the current market difficulties that are holding back exploratory projects, and resume large-scale prospecting 
activity in frontier areas, it must aggressively break the paradigm of the current exploration model. That involves adopting a new exploration model and appropriate technologies.

\section{The conventional exploration model}

The conventional exploration model that the oil and gas $(\mathrm{O} \& \mathrm{G})$ industry has been using for decades involves a certain order in the use of geophysical investigation tools, according to the level of knowledge and the size of the area being investigated. Onshore, the exploration model usually entails field observations, the use of potential and seismic methods and, finally, drilling exploratory wells. In offshore areas, some investigation methods are impossible or often not employed, so that the conventional exploration model involved entails mainly extensive use of seismic methods, before drilling exploration wells.

Generally, studies of the petroleum resource potential of a region begin with the acquisition of fundamental geological knowledge. Onshore, the first investigations are surveys of the topography and of geological attributes and features discernible from the surface. Those observations can frequently suggest fundamental aspects of the geology of a region. At this stage, explorationists seek to understand the geological framework in relation to hydrocarbon potential-whether compression or extensional forces prevail, whether sedimentary basins are present, whether there is evidence of structures favorable for the accumulation of hydrocarbons and whether there is other evidence of a functional petroleum system.

For many years, this type of study was practically the only source of information on which exploratory efforts were based, and was even utilized in order to select the most favorable drilling sites. In the case of anticline folds discernible on the surface, many successful wells were drilled in the USA, solely based on the observation of exposed anticline tops. Until well into the twentieth century, these observations were preponderant in guiding exploratory efforts (Hoswell 1934). Other empirically guided exploratory methods were also successfully employed, such as "creekology," or the drilling of successive wells along a riverbed or creek. If the first well was successful, subsequent wells drilled along the same creek had, in fact, a greater chance of being successful. Even without the understanding that we now have, regarding the geological processes that occur underground, many of those wells drilled followed the tops of anticlines. Those structures weakened surface rocks and facilitated their erosion, thus forming preferential channels for surface water flows. When drilling along such formations, those explorationists were unwittingly selecting the most favorable locations for hydrocarbon accumulations in the subsurface, and, not surprisingly, achieving greater success (Frehner 2004).

The development of remote sensing tools, such as sidelooking airborne radar (SLAR), facilitated the observation of surface features as a means of acquiring information about the subsurface. By highlighting faults, evidence of anticlines and other structures, this technology allowed exploratory methods based on surface observations to find continued use and is still used as a complementary tool in hydrocarbon exploration (USGS 2016).

As more observations are made and more knowledge is acquired and accumulated, the geological framework of the area under study becomes better understood. Other investigation tools for $O \& G$ exploration then come into play. With the advent of 2D seismic techniques that reach great depths, this technology became a fundamental part of the suite of exploration tools utilized by the $O \& G$ industry. Offshore exploration, in particular, often begins with extensive 2D seismic surveys. The visualization of geologic sections in great detail can suggest the presence of structures (traps) that may hold hydrocarbons, rock layers that may act as source rock, reservoir rock and seals, as well as faults, intrusions and rock kinetics that may provide adequate migration routes. Seismic technology can thus help define exploratory leads and their relative favorability, based on information about depths, structural organization and other information (Chopra and Marfurt 2005). All these could represent key indications to reinforce or refute evidence of a functioning petroleum system, that is, one that generated, migrated and accumulated hydrocarbons.

Non-seismic geophysical investigation tools such as surveys conducted with potential methods (gravimetric, magnetometric, electromagnetic, resistivity, magnetotelluric, etc.) have also been utilized to delineate structures and reinforce or refute indications of geological favorability for hydrocarbon accumulation, furnished by seismic surveys (Sheriff 2002). The fact that many of those tools can be employed in aerial surveys facilitates their use and reduces their cost in relation to seismic, especially onshore, where seismic acquisition is slow and onerous.

After carrying out surveys with 2D seismic and other tools, the use of 3D seismic techniques furnishes a subsurface image that is much more detailed. It is generally utilized in order to carry out surveys over areas already indicated as being more prospective, thus focusing this more expensive and detailed exploration effort over smaller, more promising areas. Despite being a more expensive technology than 2D seismic, 3D seismic furnishes a subsurface image in the form of a "seismic cube." This allows a more detailed definition of structures at the reservoir scale, as well as the use of seismic attributes that may provide evidence of fluids and reduce the inherent 
uncertainties associated with the information obtained by prior geophysical tools employed (Cartwright and Huuse 2005).

Only then, with a better visualization of possible structures that may trap fluids are exploratory (or wildcat) wells drilled, in the hope of confirming the existence of hydrocarbon accumulations that were previously only inferred. It is an axiom of the oil industry that "only drilling an oilwell can confirm the presence of oil." Since this is by far the most expensive part of the exploration process, other geophysical exploratory tools are always exhaustively employed before a wildcat well is drilled.

An exception to the rule that drilling is very expensive is the case of some onshore areas, where wells are shallow and relatively inexpensive to drill. The systematic drilling of exploratory wells was even suggested as a means of ascertaining the petroleum potential of a large region in Brazil, under the assumption that this would ensure that any existing accumulations would certainly be found (Bacoccoli 2003). Despite being obviously impractical and prohibitively expensive, this tactic almost came to be applied, since the prolific Sergipe-Alagoas basin exhibited a very favorable success rate, as well as very inexpensive wells, although the discovery size was uncertain (Aquino and Lana 1989).

\section{Constraints of the current exploration model}

The entrenched current exploration model of the O\&G industry and its associated geophysical investigation tools signify that the exploratory investigation of any frontier or other large exploratory areas will inevitably require huge investments and long lead times before reasonable knowledge about its prospectivity is accumulated. Even if the investigated area proves to be unfavorable for hydrocarbon accumulations, and no discoveries can be expected, that conclusion will only be reached after all the stages involved in the current exploration model are completed. That means that operators must assume large costs and risks that cannot be easily mitigated, regardless of the exploratory outcome.

The determination of which geophysical investigation tools are employed, and when and how they are employed, are firmly entrenched in the $O \& G$ industry. Given the fact that with this exploration model the industry has been extraordinarily successful in finding conventional O\&G resources, now estimated at approximately 3 trillion barrels worldwide (IEA 2014), it cannot be faulted for stanchly following this recipe even today.

Unfortunately, the same model that has been so successful in allowing large volumes of resources to have been discovered now effectively prevents $O \& G$ players from carrying out exploratory activities over much of the remaining prospective exploratory areas of the world. If successfully explored, those frontier areas could potentially continue providing new discoveries for the O\&G industry.

In part, this is due to the marginal attractiveness of current oil prices. This scenario is believed to be the result of a fundamental imbalance in supply and demand conditions, which would suggest that prices may be in a longterm cycle of lower equilibrium levels, rather than undergoing a market fluctuation of relatively limited duration (Dourado and Jones 2015).

However, another impediment to effective exploration of vast new frontier areas is the impractical, lengthy and onerous nature of the current exploratory model. Even offshore, new seismic 2D surveys over wide areas are prohibitively expensive, when considering the expanses involved. Furthermore, such large surveys involve acquisition and interpretation cycles that reach into years. Most operators, even those focused on high-risk, large reward plays, cannot justify such large outlays over such long time horizons, since that implies large and highly unpredictable risks.

Speculative surveys (spec surveys) carried out by acquisition companies that can then sell results to several clients have recently become more common in the seismic acquisition industry. In relation to the conventional acquisition model of surveys carried out by client demand (proprietary surveys), the alternative spec survey business model allows the cost and risk of large acquisition projects to be shared among potentially interested O\&G companies. This cost sharing also helps to prop the demand for such services when $O \& G$ players are more reluctant to invest in proprietary surveys that have large upfront costs which must be borne by a single client. Unfortunately, acquisition companies are generally still unable to afford the cost or justify the risks involved in conducting such large-scale "spec" surveys on their own.

Although there are many regions in the world considered promising exploratory plays, few industry players or governments are willing and able to jump-start their development, given the size of those plays and the risks, costs and time involved. These constraints represent the first aspect of the paradigm of the current exploration model that the oil and gas industry must break.

\section{Examples of world-class plays that remain underexplored}

Worldwide, there are many examples of potentially attractive exploratory plays that remain underexplored, and thus underdeveloped, due to the difficulties involved in financing and executing the activities dictated by the current exploratory model. 
The U.S. Geological Survey (USGS) World Petroleum Assessment 2000 (USGS 2000) reviewed and assessed many regions in the world, corresponding to known sedimentary basins with potential petroleum resources. From that overall assessment, many large assessment units, which roughly correspond to known petroleum systems, were identified as underexplored plays. Among these are areas in North America (Labrador-Newfoundland Shelf, East Greenland Rift basins), South America (GuyanaSuriname basin, Falklands Plateau), Africa (most areas along the West African coast: West-Central Coastal, Orange River Coastal, etc.), South Asia (Indus, Bombay, Ganges-Brahmaputra Delta, Irrawaddy, etc.), Asia Pacific (many, including large onshore basins in China and Southeast Asia), Former Soviet Union (large onshore basins such as West Siberian, Baykit and others) and Arctic and Antarctic regions.

In Brazil, an assessment of the yet-to-find-oil potential of a major world-class petroleum play, the presalt province, was carried out in 2011 (Jones and Chaves 2011) and 2015 (Jones and Chaves 2015). The 2015 probabilistic assessment pointed to between 176 billion (P90) and 273 billion (P10) barrels of recoverable resources. That region, however, would demand investments that are beyond the capability of the country's national oil company, Petrobras. Ever since the first major discoveries, in 2006, and given the political decision to keep all exploration and development phases under strict Petrobras control, this region has not received any significant exploratory efforts outside the current concession blocks, or the production sharing contract area of Libra. All investments foreseen are to be allocated to developing resources within and contiguous to blocks with existing discoveries, not toward new exploration efforts (TB Petroleum 2016).

Brazil also harbors other significant exploratory plays with petroleum potential, including the basins of the Equatorial Margin, an immense region of sedimentary basins over one million $\mathrm{km}^{2}$ in area. Plays in this region could represent analogs to proven plays in the West African coast, as well as to plays in the northwestern extension of the Equatorial Margin (Guyana). Significant discoveries have been made in the West African analog region (Tullow 2016) and in the northwestern extension of the Equatorial Margin (Offshore Magazine 2016). Major basins in the Equatorial Margin include Foz do Amazonas, Pará-Maranhão, Ceará, Potiguar and others, and many of these had exploration blocks included in the 11th Oil \& Gas Bidding Round by the ANP (the Brazilian national petroleum agency), in 2013, in which some blocks reached bid offers of over US $\$ 100$ million (ANP 2013). This suggests that operators are convinced of the resource potential of this region, yet the region remains extremely underexplored.
Other large, underexplored basins in Brazil include the offshore basin of Pelotas $\left(347,000 \mathrm{~km}^{2}\right)$, the deep offshore portion of Sergipe-Alagoas basin, the Espírito Santo basin $\left(194,000 \mathrm{~km}^{2}\right)$, and even onshore basins with interesting potential, such as the large Solimões $\left(440,000 \mathrm{~km}^{2}\right)$, Amazonas $\left(268,000 \mathrm{~km}^{2}\right)$, Parnaíba $\left(669,000 \mathrm{~km}^{2}\right)$ and Paraná (1,500,000 km²) basins (Milani 2007; ANP 2015).

Elsewhere in the world, the Arctic Circle, with potions claimed by several countries, such as Russia, Canada, USA and Norway, is another example of a region considered to hold vast $O \& G$ potential, but which remains largely unexplored.

\section{The pressing need to develop new exploratory plays}

The exploration, development and production of many frontier exploration plays are of strategic importance to the countries where they are located, generating significant discussion regarding geopolitical implications, and the need for additional exploration efforts and defense considerations (Judice and Jones 2016). Despite this, in general, the budgetary allocations of the national oil companies (NOCs) or the national petroleum agencies charged with conducting bidding rounds for exploration concessions are insufficient to allow them to carry out such surveys. Thus, the cost, delay and risk associated with the current exploration model hamper the development of new $O \& G$ resources in those countries.

The USGS World Petroleum Assessment 2000 indicated potentially very large volumes of recoverable resources, even at conservative (P95) probabilistic levels, for many of the world's known petroleum basins (USGS 2000). However, these estimates came with an extremely high uncertainty range, since many assessed areas are highly underexplored or are frontier basins where exploratory efforts have hardly begun. This evidences the need for significant exploratory efforts to be made, in order to more realistically ascertain the potential of these areas.

In Brazil, for example, the USGS assessed several major basins in 2012 (USGS 2012) and suggested that there are between 54 billion (P95) and 343 billion (P05) recoverable barrels of oil equivalent resources in just ten assessed Brazilian basins (Solimões, Amazonas, Parnaíba, Paraná, Foz do Amazonas, Sergipe-Alagoas, Espírito Santo, Campos, Santos and Pelotas). The figures have large uncertainty ranges, since most of these basins are still generally very underexplored.

With such large potential resources possibly present in so many prospective exploratory areas around the globe, the potential resource base involved cannot be ignored. If 
adequate exploration efforts were to be made, surely at least some of those areas would yield significant discoveries, corresponding at least to the $\mathrm{P} 95$ probabilistic values of yet-to-find economically recoverable resources.

Furthermore, when considering all forms of primary energy sources, it is important that optimization and ranking of all energy sources be considered and pursued, as a means of increasing overall economic wellbeing. This objective follows logically from the dominant paradigm in economics: Benefits (or "utility," the term utilized by economists) are maximized when resources are optimally allocated, within an efficient price system (hopefully, one that considers externalities). This concept is the foundation of modern economics since nineteenth-century neoclassical economists Menger, Jevons and Walras formalized these concepts (Bilginsoy 2015).

In today's energy scenario, where the price of all forms of energy is held down by relatively low oil and gas prices, the development of alternative fuels and energy sources finds serious impediments. These alternatives are relatively uncompetitive during the initial stages of their respective technological life cycles, since costs are initially high, before technological breakthroughs are achieved or economies of scale come into play. Today, given the current stage of the development cycle of alternative energy sources, including unconventional hydrocarbon resources, many of these resources are still uncompetitive or only marginally competitive, and their environmental footprint and life cycle impacts are not completely understood and may even be higher than that of conventional oil and natural gas (Gordon 2012).

Thus, the world faces an imperative to find, develop and produce resources that may have a lower environmental impact, and which may be more competitive than the unconventional resources that are beginning to be considered as future energy sources for the world. This objective requires that the $\mathrm{O} \& \mathrm{G}$ industry expend exploratory efforts in areas that exhibit resource potential, but remain unexplored or underexplored. Unfortunately, with the current exploration model, it will be nearly impossible to carry out the geophysical investigations required in order to confirm or refute that potential, within reasonable cost and time constraints.

The industry needs to embrace new technologies, new concepts and new approaches to doing business, if it wishes to accelerate the exploratory process, reduce costs, improve its exploratory performance and, most importantly, remain competitive. These demands on the O\&G are the second aspect of the paradigm of the current exploration model that the oil and gas industry must break.

\section{Resistance to innovation in the O\&G industry}

The O\&G industry is very conservative, despite the fact that it often touts its innovative tendency. While it has embraced and even benefitted from evolutionary, rather than revolutionary improvements in the geophysical investigation tools employed, it has not welcomed disruptive technologies, which have taken many years to become accepted, even when they have been successfully employed.

This is the case, for example, with floating production, storage and offloading rigs (FPSOs), which long ago came to be the accepted standard production technology for fasttracking new offshore fields into production. The development and production model employing FPSOs has proven to be effective, viable and reliable and has accelerated production from new deepwater fields and brought operational advantages, yet the $O \& G$ industry as a whole was very slow in embracing this model, especially in the USA. It was only in 2006 that the first FPSO for the Gulf of Mexico was approved, proposed by Petrobras, which had already established the FPSO model as its standard operating model (Offshore Technology 2008). Only in 2012 did the first Gulf of Mexico FPSO (BW Pioneer) finally enter into production, some 37 years after the first FPSO began operating in the North Sea (Oil and Gas Journal 2012). In Africa, the FPSO model only made significant inroads since 2000 , despite being a region with prime offshore potential (Offshore Engineer 2015).

There are many geophysical tools available in order to help identify and confirm or exclude the possibility of hydrocarbon accumulations in the subsurface; however, the O\&G industry is still firmly committed to following the current exploration model, relatively unchanged over the past decades. Some geophysical investigation tools available today have exhibited impressive technological advances in performance (Lambert 2015), yet petroleum exploration efforts in most regions continues to demand an extremely long, tedious and expensive process of acquisition of pertinent geological information, mostly with conventional tools, such as 2D and 3D seismic methods.

Furthermore, the current petroleum exploration model does not allow for a fundamental alteration of the order of the geophysical investigation tools employed, while still predominantly relying on the use of seismic surveys. Alternative geophysical investigation tools have barely made inroads in exploration budgets, in relation to seismic tools (Barclays Capital 2010, apud Peebler 2010, p. 5). In fact, the industry trend is to concentrate even more of its geophysical exploration budget on the most expensive

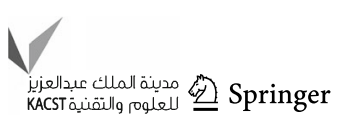


form of seismic acquisition, 3D seismic surveys, which reached over 85\% market share in 2015 (Transparency Market Research 2017). The O\&G industry still operates on the "Seismic is King" rule (Bamford 2015). This concentration of investments in a single, although very useful, geophysical investigation tool has resulted in a severe lack of diversification of tools employed, and a lack of incentive for developing and applying alternative technologies.

The obsession with seismic has been commented by researchers who lament the lack of attention, initiatives and investment dedicated to alternative or unconventional geophysical investigation technologies and methods (Wilson et al. 2015; Kleemeyer 2015). The industry routinely faces increasing challenges related to lower prices, deeper depths, greater water columns, greater need for detailed imaging and more demanding safety and environmental concerns. Until now, historical advances in the capabilities and performance of seismic technologies have been key to keeping the O\&G industry competitive, especially in new and more challenging economic and operating environments.

To a certain extent, the conservative nature of the $\mathrm{O} \& \mathrm{G}$ industry is understandable, since it deals with high-risk, high-cost exploration projects with long return periods, and drilling of exploratory wells involves decisions with extremely high costs and risks, especially in frontier regions. However, given the potential benefits that could accrue from new technologies and concepts, the inertia of the industry cannot be justified, nor its excessive focus on seismic tools, when alternative tools could bring stepchange technological advances and benefits.

\section{New geophysical investigation tools}

Today, there exist geophysical investigation tools that can almost be considered direct hydrocarbon indicators (DHIs), that is, tools that could theoretically directly suggest the existence of hydrocarbon accumulations, something that even the best seismic techniques are so far unable to do consistently and reliably. Some of these tools, such as controlled-source electromagnetic (CSEM), and other tools based on detection of electromagnetic properties, can distinguish the type of fluid present in subsurface reservoirs, based on the difference in properties and response of hydrocarbons, in relation to water. Unfortunately, they still suffer from certain limitations, such as spatial definition, depth of investigation and relatively slow and expensive aerial acquisition methods (Macgregor and Tomlinson 2014).

Another geophysical investigation tool that is still in the initial stages of development of its technological potential is magnetotelluric surveys. Magnetotelluric methods also allow the identification and distinction between different types of rocks and fluids, coming close to being a DHI. While they also have operational limitations, especially for use over large areas (Strack 2013), magnetotelluric methods can furnish valuable complementary information for subsurface mapping of carbonatic rocks or salt structures, which are normally challenging even for the most sophisticated seismic tools (Zhdanov et al. 2011).

Geophysical investigation tools based on electromagnetic properties are supported by fundamental concepts of physics and the electromagnetic behavior of different materials that have long been known to scientists. However, in general, their commercial application is still incipient, since they generally require acquisition equipment that renders their surveys relatively expensive in relation to seismic methods, especially offshore, where seismic acquisition is relatively competitive.

Geophysical investigation tools based on the principle of seep detection (small leaks entailing hydrocarbon fractions that can travel from reservoirs to the surface, even if in minute quantities) may be applied at different acquisition scales. These range from the detection of seeps to confirm the existence of working petroleum systems in large regional surveys (Shengwei 2012), to reservoir and even well scale detection of hydrocarbon fractions directly leaking from specific accumulations, achieved with ultrasensitive sea-bottom detection systems (Mcconnell 2016). They can indicate the presence of a working petroleum system, yet cannot guarantee the existence of a hydrocarbon accumulation in a reservoir.

Gravity-based geophysical investigation tools have also improved markedly in the last few years and today include both gravimetry and gravity gradiometry technologies that can provide very detailed density imaging of the subsurface, down to the reservoir scale. Such tools have been very effective in order to provide complementary geological, structural and fluid information (Nabighian et al. 2005). They also come close to being a DHI, since lower-density hydrocarbon accumulations can be directly inferred by advanced gravity gradiometry tools. Because gravity detection (based on mass density) is independent from other potential field methods, such as seismic or electromagnetic tools, its value also lies in providing an independent confirmation or denial of hydrocarbon accumulation potential. In particular, full tensor gradient (FTG) gravity data acquisition entails measuring the horizontal gravity tensor components (Txx, Tyy, Txy, Txz and Tyz), as well as the vertical tensor component (Tzz), with sensitive gravimeters (Murphy and Brewster 2007). These components represent the spatial rate of change of gravitational acceleration and have a much more precise response than the gravity magnitude vector, allowing a better estimate of depth and composition of targets. 
Finally, another geophysical investigation tool available is a technology that allows the identification of subsurface stress regime anomalies. Stress field detection (SFD) anomalies are generally present in the case of major geological features, such as faults, folds, salt kinetics and others. More importantly, lateral stress regime anomalies are also involved in regions where fluids are trapped in reservoirs, giving rise to pressured regions. The different stress regimes represent subsurface stress anomalies that can be interpreted to point to possible fluid accumulations. Besides hydrocarbons (oil or gas), other trapped fluids, such as water, brine, non-hydrocarbon gases, can produce such anomalies. However, the possibility of identifying confined fluids is novel and important, since it allows not only the identification of prospective (hopefully hydrocarbon) fluid accumulations, but also the identification of areas without fluid accumulation. This is particularly valuable in excluding such areas from further exploratory efforts, thus limiting expenditures of exploration efforts, if the presence of confined fluids is unlikely.

SFD involves the detection of minute gravitational field perturbations due to the effect of subsurface stress changes along an investigated survey route, an effect that is detected with interferometry techniques, which have recently been widely used in gravitation field detection, instead of conventional gravimetry (Anderson et al. 2011). Since all forms of energy are sources for the gravitational field, stress energy can lead to changes in its direction and magnitude, and detection of such anomalies can provide a proxy detection method for associated occurrences of fluids confined in reservoirs. Various researchers have proposed the use of gravity tensor changes as potential geophysical methods (Bongs and Kruger 2012; Schmidt et al. 2011; Jqi 2010; Liszicasz and Mustaqeem 2012; New Scientist 2017). These effects are not related to the density effects on the gravity tensors that FTG exploits, since in this case, quantum gravity tensor disturbances are being observed.

Stress field detection technology also has the advantage of being able to be acquired aerially, at high speeds, and acquisition data does not have to be further processed in order to be interpreted, which reduces costs and time spent on acquisition. However, this geophysical investigation tool does not provide 3D visualization of the surveyed area, nor does it provide depth information for the indicated anomalies. Furthermore, lateral resolution is relatively low in relation to structural definition tools, such as 3D seismic, so it is most effective in surveys over large areas, when searching for large hydrocarbon pools, as is usually the objective in frontier areas, where, initially, only the most significant accumulations would be of interest. However, this technology remains limited to a single commercial supplier of geophysical surveys, and it must be complemented with the use of other geophysical investigation tools, in order to obtain detailed structural and other information that can be used in final exploration decisions.

\section{A new exploration model for the O\&G industry}

The new exploration model that the $O \& G$ industry must adopt needs to shorten the time required for pertinent geological knowledge to be acquired, it must lower costs of the exploration process itself, and it must allow risk reduction measures to be applied to the exploration process. This last requirement is extremely important, since unacceptable risks that cannot be mitigated are the main impediment to investing in exploration projects conducted by potential operators.

In order for risk reduction measures to be available to operators, the exploration model employed should allow the $O \& G$ industry to effectively and efficiently explore and find petroleum resources, but if initial investigations suggest that the investigated area does not exhibit adequate discovery potential, it should allow exploration efforts to be terminated before large, unrecoverable expenditures are made.

Breaking the current exploration model of the O\&G industry implies adopting a new concept in petroleum exploration. The objective is to first obtain indications of the existence of possible hydrocarbon accumulations. Only afterward, if any such accumulations were to be indicated, would additional investigations be conducted, including using conventional geophysical tools (seismic, etc.). This involves a profound inversion of the order in which the various stages of the conventional exploratory model are performed. However, it also requires the use of geophysical tools that could suggest an independent and direct indication of hydrocarbon accumulation potential, while being relatively inexpensive, fast and easy to employ right at the beginning of the exploratory process, over large areas.

While such requirements would seem to be overly demanding, such tools would not have to provide much detail or other geologically pertinent information. At this early stage of the exploratory cycle, the main objective is merely to obtain an indication of the existence or absence of possible prospective areas, not a full delineation of the regional or local geology, or of the prospects themselves.

As described above, there are many effective geophysical investigation tools available in the suite of tools that the O\&G industry can employ. The tools employed do not necessarily need to be infallible or even be able to pinpoint hydrocarbon accumulations very accurately, since other tools available could help verify and further define such accumulations. Thus, it would be possible to obtain an indication of whether a region warrants further exploration efforts, even before seismic methods (2D or 3D) are 
employed, and possibly even before a thorough understanding has been acquired about the underlying geological framework of the region.

Fortunately, although this was not the case in the past, today, this new exploration model, and the associated geophysical investigation tools required for it to be effectively implemented are available and technically and economically viable.

\section{First experiences with a new exploration model}

Although the new exploration model for the O\&G industry has not yet been widely employed in large exploration projects, there are cases where this new model has been applied, at least in part, in an effort to benefit from the advantages of the significant acceleration of the exploration process and the reduction in costs that it affords.

\section{Pakistan}

In Pakistan, in the Kharan Forearc basin (KFB), exploration efforts over a relatively large land area had been absent for decades. However, Pakistan's limited reserves and small $O \& G$ production in relation to its fast-growing demand led authorities to embark on an aggressive strategy to increase its resource base. The path chosen in 2013 was to execute a survey over the KFB, covering approximately $30,000 \mathrm{~km}^{2}$, utilizing the stress field detection method. This survey method allowed the operator to obtain a map of the observed and identified subsurface stress anomalies, which were interpreted to provide a direct indication of areas with highest likelihood of hydrocarbon accumulations (Liszicasz et al. 2013).

This approach represented an important break from the paradigm of the conventional exploration model of the O\&G industry. That model would have involved starting the exploration process by carrying out extensive 2D seismic surveys, then, 3D seismic would have been acquired over areas judged to contain prospective structures (leads), and finally, additional geophysical investigation tools would be used, in order to reduce the uncertainty regarding the existence of hydrocarbon accumulations (dry hole risk). In this case, just as envisioned by the proposed new exploration model, further seismic acquisition was planned after initial anomalies were indicated, not before. While the SFD survey was delayed, and some seismic acquisition ended up being acquired concomitantly, the exploration strategy adopted envisioned subsequent seismic acquisition, in order to produce a detailed structural map of the anomalies indicated by the initial SFD survey (Khan 2013).
The survey area comprised a large, remote and inhospitable terrain, subject to significant security issues. The entire campaign was completed in only a few months. To similarly identify areas of likely hydrocarbon accumulation, a conventional 2D and 3D campaign over such an area would have been impossible to execute with a similar budget, and it would have taken much longer to acquire and interpret the data and deliver results.

The conclusions presented from this experience suggest that the integration of seismic information with the results from the SFD survey shows a very good correlation between the anomalies identified by the SFD survey and the structural/stratigraphic leads indicated by seismic. The exploration model utilized also allowed the SFD survey to detect geological structural elements that could act as fluid traps. Furthermore, integration of these exploration tools helped mitigate the risk associated with trap failure and allowed a ranking of the identified leads, furnishing a valuable decision aid (Khan 2013).

Thus, a case in which the current exploration model was discarded in favor of a completely new approach, involving a reversal of the order in which geophysical acquisition tools are employed, successfully reduced costs and reduced the time required to reach prospect drilling decisions.

\section{Mexico}

In Mexico, the southern Gulf of Mexico has provided important discoveries, including Cantarell field, a supergiant field that has produced over 7 billion barrels of oil for Mexico. However, Mexico's relatively unfavorable legal framework for petroleum exploration had discouraged exploratory activities until 2014, when a new hydrocarbons law was passed, which substantially improved the attractiveness of exploratory efforts in the country. Thus, in the last years Mexico experienced sharp declines in production from existing fields and did not make significant discoveries. Mexico was in the uncomfortable position of possibly becoming oil dependent, after years of being a significant exporter, while it had already become a net gas importer in 2000, negatively affecting its economy (Seelke et al. 2015).

Given the dire outlook for its petroleum resource base and production, there was strong pressure to make up for lost time in exploratory efforts. In 2012, Mexican national oil company PEMEX, at that time the sole O\&G operator in the country, decided to embark on an aggressive exploration campaign, seeking to reverse the trend in past discoveries and to accelerate the exploratory process of the region. It was clear that following a conventional exploration model would have resulted in a very expensive and slow process, incompatible with capital budgets and the urgent exploratory needs of the country. 
Furthermore, the stark differences in exploration and production activity between the northern (US) and southern (Mexico) sectors of the Gulf of Mexico, both onshore and offshore, begged the question of whether nature had provided very different geological favorability for $O \& G$ in each sector, or had Mexico simply been remiss in its own exploration efforts. The aging Mexican onshore fields, and the few but sizeable discoveries in the Mexican offshore sector, suggested that the latter case was the more likely, so the exploratory potential of the Mexican sector warranted urgent assessment.

In order to avoid some of the insurmountable costs and delays associated with an exploratory campaign conducted according to the conventional exploratory model, the initial survey method chosen was a widely spaced geophysical investigation with the SFD method, covering a large area of over $200.000 \mathrm{~km}^{2}$. The exploratory campaign provided verification opportunities because the survey area included areas with known hydrocarbon accumulations that had prior seismic coverage available, as well as results from other geophysical acquisition tools, such as gravity gradiometry and magnetometry (Escalera et al. 2013).

The survey lines flown were widely spaced and directed toward specific regions of interest, so that they were more like analogs to 2D seismic lines, although their results provide entirely different types of information. While a $2 \mathrm{D}$ survey would show geological features in an interpreted section, the SFD survey only provided indications of areas with potential hydrocarbon accumulations. Nevertheless, strong evidence was produced in favor of the usefulness of executing an exploration campaign that did not follow the conventional exploration model. The initial exploration stage relied, instead, on a geophysical investigation tool that directly provided an indication of possible hydrocarbon accumulations.

Based on the comparison studies between the results from the unconventional survey method and prior geophysical information available, it was concluded that there was a high correlation between the survey anomalies indicated and the known hydrocarbon accumulations that had already been producing. The SFD anomalies exhibited significant correlation with seismically interpreted structures of interest, regardless of water depth or the presence of salt, and were most effective at detecting anomalies with a linear extent greater than $2 \mathrm{~km}$. It was also concluded that employing the alternative exploration model can provide savings in time and cost required to conduct the campaign, allowing subsequent geophysical investigation steps to be focused on the survey anomalies indicated (Escalera et al. 2013).

Since the region of the Mexican exploration campaign could contain geological structures and features that are typically challenging for seismic acquisition, such as salt bodies, there were important and pertinent concerns regarding the effectiveness of the new exploration model and the SFD method in unknown geological settings. The comparison studies concluded that the alternative exploration model employed was, indeed, effective in identifying hydrocarbon accumulation targets in different lithologies (carbonates, terrigenous sediments), different environments (onshore, offshore), varying water depths, different geological settings (different types of traps) and over/under/next to different structures (salt bodies) (Escalera et al. 2013).

Large accumulations were of greatest interest, since a large area with a relative absence of recent activity and discoveries would require a large prize to justify investments in new O\&G projects. Thus, the designed SFD survey crossed a total of 64 known hydrocarbon accumulations of various sizes, containing 12.05 billion bbl of 3P reserves, of which 47 were successfully identified (73\%). However, the 47 anomalies represented 11.92 billion bbl of the total reserves; thus, the positive identification of known reserves was close to $99 \%$. The unidentified 17 accumulations were primarily in isolated locations and had a linear extent of less than $2 \mathrm{~km}$.

Even if only large targets could be identified when employing a new exploration model using a wide spacing for the unconventional survey method employed, the results of the exploratory campaign demonstrated a successful case of breaking the current paradigm of the exploration model, in favor of employing the new exploration model proposed.

\section{Bolivia}

In Bolivia, another instance of an exploration campaign that broke the paradigm of the current exploration model of the $O \& G$ industry took place. In this case, the motivation was to expand hydrocarbon exploration in Bolivia, since the country is a large gas exporter to Brazil and Argentina, yet its discovery rate of new gas accumulations has not kept pace with production. Given its relatively restrictive legislation and generally unfavorable political situation and regulatory framework, there has been a lack of significant foreign investment. Thus, the country was compelled to accelerate exploration activities, and since YPFB, the national oil company of Bolivia, would not have been able to carry out an exploration campaign according to the current exploration model of the O\&G industry, a new approach was adopted.

The exploration campaign undertaken had the main objective of directly investigating possible hydrocarbon accumulations, which could allow discovery and production to begin much sooner than under a conventional exploration campaign. Another objective was to suggest 
new exploration targets for future campaigns, in order to establish a sustained flow of new leads and discoveries. A third objective was to evaluate the effectiveness of the unconventional survey method employed in directly identifying hydrocarbon accumulations. If it were shown to be effective, the new exploration model could more confidently continue to be employed in the country, as a part of its exploration strategy (Belmonte et al. 2016).

As in the case of Mexico, the SFD survey employed as part of the exploration strategy proved to be effective in identifying known hydrocarbon accumulations. In addition, the survey was able to produce a map of ranked anomalies indicative of hydrocarbon accumulation potential, which provided indications of numerous prospective leads. As a further demonstration that the exploration campaign was committed to a new exploration model for its activities, additional conventional geophysical investigations were planned after, not before, the initial survey was completed. Just as the proposed exploration model would suggest, detailed geophysical investigations, including seismic, were subsequently conducted and are still planned. These involve integration studies between existing geophysical information and SFD survey results, as well as additional SFD surveys (Belmonte et al. 2016).

An important conclusion from this case was the confirmation of the viability of executing an exploration campaign on a national level, without following the procedures dictated by the current exploration model of the $O \& G$ industry. This approach demonstrated that an alternative exploration model and the use of an unconventional survey method could successfully achieve multiple objectives, such as lead generation in frontier areas, lead confirmation in areas where existing geophysical information suggested prospectivity, and establishing a novel framework for a national exploration strategy.

\section{Conclusion}

As now practiced, the current exploration model of the oil and gas industry condemns it to a long and onerous process, when surveying large frontier areas. Due to the high cost and delay, many possibly attractive areas are thus left unexplored for long periods, especially in a marginally attractive oil price environment. This situation is exacerbated when conventional investment sources are scarce, or when other limiting factors, such as political or regulatory aspects impede adequate exploration efforts.

Faced with a challenging economic scenario and the need to prospect immense frontier areas that could provide new and rewarding exploratory opportunities, the oil and gas industry needs to adopt a new exploration model, focused on a faster, less expensive and more direct way of identifying and assessing prospective leads. New and emerging technologies are the key to achieving this change. Fortunately, several of these technologies are now available, and they have proven to be effective and compatible with the new exploration model proposed.

If the world economy is to develop in a way that prioritizes the development of the resources with the most favorable economic and environmental characteristics, they must first be known and discovered. This requires that exploration efforts be directed toward many unexplored and underexplored regions in the world. For this to happen, the O\&G industry must overcome the constraints of the current exploration model that it employs, especially those related to the large risk of exploration campaigns in frontier areas. A new exploration model and new geophysical investigation tools that allow faster and less expensive exploration cycles would open many heretofore-unexplored areas with potential hydrocarbon accumulations to economic exploration efforts.

Many regions in the world have vast areas that could benefit from the adoption of a new exploration model that would allow a faster, more objective and more competitive path to ascertaining their resource potential. Various successful experiences in employing the new exploration model proposed suggest that this approach is indeed viable.

Executing preliminary surveys over large, unexplored or underexplored areas, obtaining prospectivity information upfront and reducing the time, cost and risk of exploratory campaigns are no longer an impossibility. It has been shown to be possible, by breaking the paradigm of the current exploration model that the $O \& G$ industry has long used. In the new exploration model proposed, conventional geophysical acquisition tools are not replaced, but utilized in different ways, in conjunction with new geophysical acquisition tools that are compatible with that new exploration model.

Furthermore, quantitative results suggest that the proposed new exploration model can identify existing hydrocarbon accumulations with high confidence, shorten the exploration cycle, reduce costs of exploratory campaigns and jump-start the development of exploratory areas.

Open Access This article is distributed under the terms of the Creative Commons Attribution 4.0 International License (http:// creativecommons.org/licenses/by/4.0/), which permits unrestricted use, distribution, and reproduction in any medium, provided you give appropriate credit to the original author(s) and the source, provide a link to the Creative Commons license, and indicate if changes were made.

\section{References}

ANP - National Agency of Petroleum, Natural Gas and Biofuels (2013) Report of the 11th bidding round. http://www.brasil-rounds.gov. br/arquivos/relatorio_r11/Relatorio_Analise_R11.pdf 
ANP - National Agency of Petroleum, Natural Gas and Biofuels (2015) Summary of the sedimentary basins. http://www.brasilrounds.gov.br/arquivos/areas_oferecidas_r13/BasinsSummary_ v21052015.pdf

Anderson BM, Taylor JM, Galitski VM (2011) Interferometry with synthetic gauge fields. Phys Rev A 83:031602(R). https://arxiv. org/abs/1008.3910

Aquino GS, Lana MC (1989) Exploração da Bacia de SergipeAlagoas. In: Seminário de Interpretação Exploratória, Rio de Janeiro. Technical presentations, Rio de Janeiro: Petrobras, Depex. pp 97-104

Bacoccoli G (2003) Petróleo no Brasil. Class syllabus and presentation, Petróleo de A a Z, Clube do Petróleo, Rio de Janeiro, Brazil

Bamford D (2015) Welcome and introduction. In: Non-seismic geophysics. The Geological Society, London, UK. Feb 2015. http://www.findingpetroleum.com/agenda/Nonseismic-Geophysics/ f37a5.aspx

Belmonte M, Padilla O, Liszicasz G, Hung E, Tippu R (2016) Advancing YPFB's hydrocarbon exploration programs in the Bolivian sedimentary basins using the leading-edgeSFD ${ }^{\circledR}$ airborne geophysical survey method. In: XII bolivarian symposium, Bogotá, Colombia, 26-28 Sep 2016. http://www.nxtenergy.com/ upload/media_element/193/a99ba994b146/xii_simposio_poster_ nxt_final_english.pdf

Bilginsoy C (2015) A history of financial crises: dreams and follies of expectations. Routledge, New York. ISBN 978-0-415-68724-9

Bongs K, Kruger P (2012) Unveiling the underground. Phys World. doi:10.1088/2058-7058/25/01/32

Cartwright J, Huuse M (2005) 3D seismic technology: the geological 'Hubble'. Basin Res 17:1-20. doi:10.1111/j.1365-2117.2005. 00252.x

Chopra S, Marfurt KJ (2005) Seismic attributes-a historical perspective. SEG Geophys 70(5):3SO-28SO. doi:10.1190/1. 2098670

Dourado JDA, Jones CM (2015) New oil market paradigm-the Brazilian perspective. T\&B Pet Mag 16(37):54-60. http:// tbpetroleum.com.br/magazines/

Escalera JA, García MV, Olazarán JJH, Ponce AT, García OV, Cardador MH, Liszicasz G (2013) Application of Stress Field Detection $\left(\mathrm{SFD}^{\circledR}\right)$ technology for identifying areas of hydrocarbon potential in the gulf of Mexico region. In: Next generation oil \& gas summit Latin America, Cartagena, 23-25 Jul 2013. http://citeweb.info/20132178765

Frehner B (2004) From creekology to geology: finding and conserving oil on the Southern Plains, 1859-1930. Thesis (PhD), The University of Oklahoma, 2004. Pub. Number AAI3270678. ISBN: 9780549086079

Gordon D (2012) The challenges of unconventional oil. http:// carnegieendowment.org/2012/06/05/challenges-ofunconventional-oil-pub-48535

Hoswell JV (1934) Historical development of the structural theory of accumulation of oil and gas: Part I. History. In: AAPG SP 6: problems of petroleum geology, 1934. http://archives.datapages. com/data/specpubs/methodo1/data/a069/a069/0001/0000/0001. htm

IEA- International Energy Agency (2014) World energy outlook 2013 http://www.iea.org/publications/freepublications/ publication/world-energy-outlook-2013.html

JQI-Joint Quantum Institute (2010) A new design for a gravimeter-a new design for gravity detection. http://jqi.umd.edu/news/ new-design-gravimeter

Jones CM, Chaves HAF (2011) Assessment of yet-to-find oil in the Brazilian pre-salt region, paper SPE-143911-MS. ISBN 978-161399-123-7. In: Brasil Offshore 2011, Macaé. OnePetro Conference Papers, Richardson, TX, USA: Society of Petroleum
Engineers. https://www.onepetro.org/conference-paper/SPE143911-MS

Jones CM, Chaves HAF (2015) Re-assessment of yet-to-find oil in the pre-salt province of Brazil, presentation. In: 14th international congress of the Brazilian Geophysical Society, Rio de Janeiro, Aug 2015. http://library.seg.org/doi/abs/10.1190/sbgf2015-002

Judice LPC, Jones CM (2016) Clausewitz e a Polarização Marítima no Século XXI: uma orientação teórica para a estratégia nacional de defesa. Revista Brasileira de Estudos Estratégicos: Instituto de Estudos Estratégico da Universidade Federal FluminenseINEST/UFF 8(16), Rio de Janeiro, Brazil. ISSN 1984-5642 (online edition). http://www.inest.uff.br/index.php/rest/inicio

Khan MR (2013) SFD (stress field detection) and its integration with seismic in Kharan forearc basin and its implications for hydrocarbon exploration in a frontier area. In: AAPG ICE, Cartagena, Colombia. https://prezi.com/cschc619vuvu/sfd-stressfield-detection-and-its-integration-with-seismi/

Kleemeyer G (2015) Technology focus: seismic applications. J Pet Technol 67(3). https://www.onepetro.org/journal-paper/SPE0315-0136-JPT

Lambert M (2015) Seismic sector is still a reliable E\&P market indicator. Executive Viewpoint, World Oil Magazine 236(4). http://www.worldoil.com/magazine/2015/april-2015/columns/ executive-viewpoint

Liszicasz G, Mustaqeem A, Khan MR, Bhatti MA, Hussain A (2013) $\mathrm{SFD}^{\circledR}$ (Stress Field Detection) and its integration with seismic in Kharan Forearc basin and its implications for hydrocarbon exploration in a frontier area. In: SPE/PAPG Annual technical conference, 25-27 Nov, 2013, Islamabad, Pakistan. http://www. searchanddiscovery.com/pdfz/abstracts/html/2015/90208papg/ abstracts/lisz.pdf.html

Liszicasz G, Mustaqeem A (2012) Using airborne stress field detection ("SFD $\left.{ }^{\circledR} "\right)$ surveys as an exploration tool: a comparative of SFD ${ }^{\circledR}$ data to known reservoirs. In: Proceedings of the indonesian petroleum association on 36th annual convention and exhibition, May 2012. http://archives.datapages.com/data/ipa pdf/083/083001/pdfs/IPA12-G-166.htm

Macgregor L, Tomlinson J (2014) Marine controlled-source electromagnetic methods in the hydrocarbon industry: a tutorial on method and practice. Interpretation. doi:10.1190/INT-20130163.1

Mcconnell D (2016) Modern geochemistry methods to prove working petroleum systems: applications for Offshore Myanmar. Search and Discovery Article \#41795, 2016. http://www. searchanddiscovery.com/documents/2016/41795mcconnell/ndx mcconnell.pdf

Milani EJ (2007) Bacias sedimentares Brasileiras. Boletim de Geociências da Petrobras 15(2). http://vdpf.petrobras.com.br/ vdpf/todasEdicoes.do

Murphy CA, Brewster J (2007) Target delineation using full tensor gravity gradiometry data. ASEG Extended Abstracts 1(3). https://doi.org/10.1071/ASEG2007ab096

Nabighian MN, Ander ME, Grauch VJS, Hansen RO, Lafehr TR, Li Y, Pearson WC, Peirce JW, Phillips JD, Ruder ME (2005) Historical development of the gravity method in exploration. Geophysics 70(6). http://library.seg.org/doi/abs/10.1190/1. 2133785? journalCode=gpysa7

New Scientist (2017) Quantum gravity detector will use atom clouds to survey for oil. Online 01 Aug 2017. https://www.newscientist. com/article/2142507-quantum-gravity-detector-will-use-atomclouds-to-survey-for-oil/

Offshore Engineer (2015) West Africa an FPSO hot spot. Online Mar 09, 2015. http://www.oedigital.com/component/k2/item/8397west-africa-an-fpso-hot-spot

Offshore Magazine (2016) Exxon to fasttrack giant Liza discovery offshore Guyana. Online 18 Nov 2016. http://www.offshore-

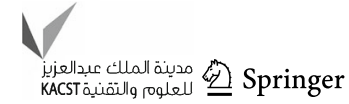


mag.com/articles/2016/11/exxon-to-fasttrack-giant-lizadiscovery-offshore-guyana.html

Offshore Technology (2008) The dominance of FPSO. Online 29 Aug 2008.

http://www.offshore-technology.com/features/ feature40937/

Oil \& Gas Journal (2012) First gulf of Mexico FPSO receiving Cascade oil. Online Mar 02, 2012. http://www.ogj.com/articles/ 2012/03/first-gulf-of-mexico-fpso-receiving-cascade-oil.html

Peebler B (2010) ION and the seismic sector. In: Barclays capital 2010 CEO energy-power conference, New York, 15 Sep 2010. http://phx.corporate-ir.net/External.File?item=UGFyZW50SUQ9 NjMwNTB8Q2hpbGRJRD0tMXxUeXBIPTM=\&t=1

Schmidt M, Senger A, Hauth M, Freier C, Schkolnik V, Peters A (2011) A mobile high-precision absolute gravimeter based on atom interferometry. Gyrosc Navig. doi:10.1134/ S2075108711030102

Seelke CR, Ratner M, Villarreal MA, Brown P (2015) Mexico's oil and gas sector: background, reform efforts, and implications for the United States. Congressional research Service report for members of congress, R43313. https://fas.org/sgp/crs/row/ R43313.pdf

Shengwei S (2012) The exploration and evaluation of petroleum resource based on remote sensing technology. Phys Proc 22:1119-1123. http://www.sciencedirect.com/science/article/pii/ S1875389212014964

Sheriff RE (2002) Encyclopedic dictionary of applied geophysics. SEG Geophys Ref Ser. ISBN (online): 978-1-56080-296-9

Strack KM (2013) Advances in electromagnetic methods for hydrocarbon applications. In: 10th Biennial international conference and exposition, Kochi, India. Soc. of Petroleum Geophysicists, India. http://www.spgindia.org/10_biennial_form/P438.pdf

TB Petroleum (2016) Flexibility in the rules will attract more investment to the sector, says IBP. Online 13 Oct 2016. http:// tbpetroleum.com.br/news/flexibility-in-the-rules-will-attractmore-investment-to-the-sector-says-ibp/

Transparency Market Research (2017) Global marine seismic equipment and acquisition market: snapshot. http://www. transparencymarketresearch.com/marine-seismic-equipmentacquisition-market.html

Tullow (2016) Jubilee field. http://www.tullowoil.com/operations/ west-africa/ghana/jubilee-field

USGS (2000) USGS World Petroleum Assessment 2000. https://pubs. usgs.gov/dds/dds-060/index.html\#TOP

USGS (2012) Assessment of undiscovered conventional oil and gas resources of South America and the Caribbean, 2012. World Petroleum Resources Project. https://pubs.usgs.gov/fs/2012/ 3046/fs2012-3046.pdf

USGS (2016) Side-Looking Airborne Radar (SLAR) Mosaics. https:// lta.cr.usgs.gov/SLAR

Wilson H, Nunn K, Luheshi M, Reid A, Mcgregor L, Makris J, Raikes S, Jack I (2015) A review of specialist geoscience technologies. In: Non-seismic geophysics. The Geological Society, London, UK. http://e2ab2795878289afcc94-5f07cf287e13b4eba5efff33cf d882b2.r30.cf1.rackcdn.com/slr.pdf

Zhdanov MS et al (2011) Large-scale 3D inversion of marine magnetotelluric data: case study from the Gemini prospect, Gulf of Mexico. SEG Geophys. doi:10.1190/1.3526299

\section{Publisher's Note}

Springer Nature remains neutral with regard to jurisdictional claims in published maps and institutional affiliations. 